\title{
ESTIMATIVA DO FLUXO DE CALOR NO SOLO EM ÁREA URBANA POR IMAGENS DO SENSOR TM LANDSAT 5
}

\author{
Elvis Bergue Mariz Moreira ${ }^{(a)}$, Deivide Benicio Soares ${ }^{(b)}$, Eberson Pessoa Ribeiro ${ }^{(c)}$, Henrique \\ dos Santos Ferreira ${ }^{(\mathrm{d})}$
}

(a) Doutor em Geografia, Prof. da Universidade Federal do Oeste da Bahia / UFOB, Campus Barreiras, Centro das Humanidades, Curso de Geografia, elvis.moreira@ufob.edu.br

(b) Doutor em Geografia, Grupo de Estudos em Climatologia Tropical e Eventos Extremos (Tropoclima)/UFPE, deividebenicio@yahoo.com.br

(c) Doutor em Geografia, Prof. do Instituto Federal de Pernambuco, Campus Vitória de Santo Antão, eberson.pessoa@ vitoria.com.br

(d) Doutorando do Programa de Pós-Graduação em Geografia, PPGEO, UFPE,

\section{Eixo: GEOTECNOLOGIAS E MODELAGEM ESPACIAL EM GEOGRAFIA FÍSICA}

\begin{abstract}
Resumo
O fluxo de calor no solo $(\mathrm{G})$ é o resultado da transferência de energia disponível a partir da radiação líquida, tranferida para aquecimento da superfície. O objetivo principal dessa pesquisa consistiu em estimar o fluxo de calor no solo da cidade de Recife - PE. Foram utilizadas seis imagens digitais do sensor TM - Landsat 5, com órbita 214 e pontos 65, 66, processadas através do software Erdas Imagine. Os resultados encontrados destacou valores de $\mathrm{G}$ superiores a $70 \mathrm{Wm}^{-2}$ no setor leste da cidade, onde há predomínnio de impermeabilização da superfície com materiais absorvedores de calor, enquanto as áreas com predomínio de vegetação situados nos recortes com fragmentos de mata e manguezal, apresentaram intervalos entre 45 a $60 \mathrm{~W} \mathrm{~m}^{-2}$. A superfície urbana contribui com os maiores valores de radiação disponível para aquecimento do solo e formação das ilhas de calor.
\end{abstract}

Palavras chave: Ilhas de calor, área urbana, sensoriamento remoto, balanço de energia

\section{Introdução}

Nas últimas décadas o solo nas áreas urbanas tem apresentado elevado crescimento em percentuais de impermeabilização, fato observado no intenso adensamento construtivo comum nos grandes centros urbanos. Esse crescimento tem favorecido o armazenamento de calor transferido para aquecimento da superfície, resultando em áreas suscetíveis a formação das ilhas de calor (MOREIRA, 2014). Seja pela implosão demográfica e/ou pela explosão das atividades, os espaços urbanos passaram a assumir a responsabilidade do impacto máximo da atuação humana sobre a organização na superfície terrestre e na deterioração do ambiente (MONTEIRO, 1990).

O fluxo de calor no solo exerce grande influência na formação das zonas quentes, baseando-se na premissa que a condutividade térmica e a capacidade de armazenar calor dos materiais urbanos são maiores que os solos providos de vegetação (MAITELLE, 2010). O processo de mensuração deste 
parâmetro apresenta-se complexo quando comparado com outros componentes do balanço de energia estimados via sensoriamento remoto (BASTIAASSEN, 1998; BEZERRA, 2006).

Diversos fatores exercem influencia nesse parâmetro, tendo seu aquecimento superficial condicionado pelo percentual de radiação solar absorvida, sendo assim destacasse como dependente da radiação solar, propriedades do solo e tipo de cobertura vegetal com grande variação temporal e espacial.

Conforme mencionam Grimmond e Oke (1999a), com exceção de grandes corpos de água, o fluxo de calor armazenado no dossel urbano é aproximadamente 2 a 6 vezes maior do que o de um dossel natural, atingindo valores máximos entre $150 \mathrm{~W} \mathrm{~m}^{-2}$ e $300 \mathrm{~W} \mathrm{~m}^{-2}$. Portanto, para descrever adequadamente as trocas de energia em superfícies urbanas é importante quantificar o fluxo de calor armazenado no dossel urbano (ROBERTS et al., 1984; GRIMMOND e OKE, 1999a; GRIMMOND e OKE, 1999b; BROWN, 2000).

Diante disso, esse trabalho tem como principal objetivo a estimativa do fluxo de calor no solo através de imagens digitais do sensor TM Landsat 5 na cidade do Recife.

\section{Metodologia}

O objeto do estudo é a cidade do Recife localizada a $8^{\circ} 04^{\prime} 03^{\prime \prime}$ de latitude Sul e $34^{\circ} 55^{\prime} 00^{\prime \prime}$ de longitude Oeste, Figura 1, capital do estado de Pernambuco, localizada no litoral do Nordeste brasileiro na porção centro leste da região. A cidade compreende uma área territorial de $217.494 \mathrm{~km}^{2}$, limitando-se, ao norte, com as cidades de Olinda e Paulista, ao sul com o município de Jaboatão dos Guararapes, Oeste com São Lourenço da Mata e Camaragibe e ao leste com o Oceano Atlântico.

A cidade mantém acelerado ritmo de crescimento da sua população tendo, na segunda metade do século XX, ultrapassando um milhão de habitantes. Segundo dados do IBGE/2010, a região metropolitana do Recife é a mais populosa do Nordeste e a quinta maior do Brasil ao lado de Fortaleza e Salvador. Com uma população de 1.533.580 milhões de habitantes e total de 3,73 milhões em toda área metropolitana, sendo considerada uma das cidades com maior desenvolvimento econômico do Nordeste do Brasil. A metrópole tem como forte característica o comércio, o qual teve início no período da economia açucareira com o Porto do Recife. Sua função e hierarquia acompanharam o ritmo das transformações socioeconômicas do Brasil, e atualmente é um dos mais importantes centros de serviços e distribuição de mercadorias da região Nordeste. 


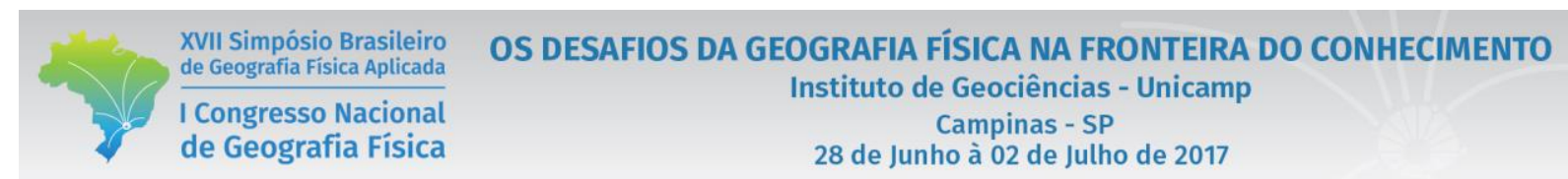

O crescimento urbano, seguido da ausência de uma eficiente fiscalização por parte do poder público, provoca o crescimento de áreas asfaltadas e diminuição das vegetadas, ou seja, modificação no uso e cobertura do solo o que tem acelerado importantes modificações nos componentes do balanço de energia.

Somado a este crescimento e ao surgimento de novas fábricas e industrias para o suprimento de bens em gerais, surgem os problemas de ordem ambientais atrelados a substituição das áreas verdes por superfícies urbanizadas em benefícios da especulação imobiliária, proporcionando modificações nas trocas de energia entre a superfície e atmosfera e contribuindo para o surgimento das ilhas de calor.

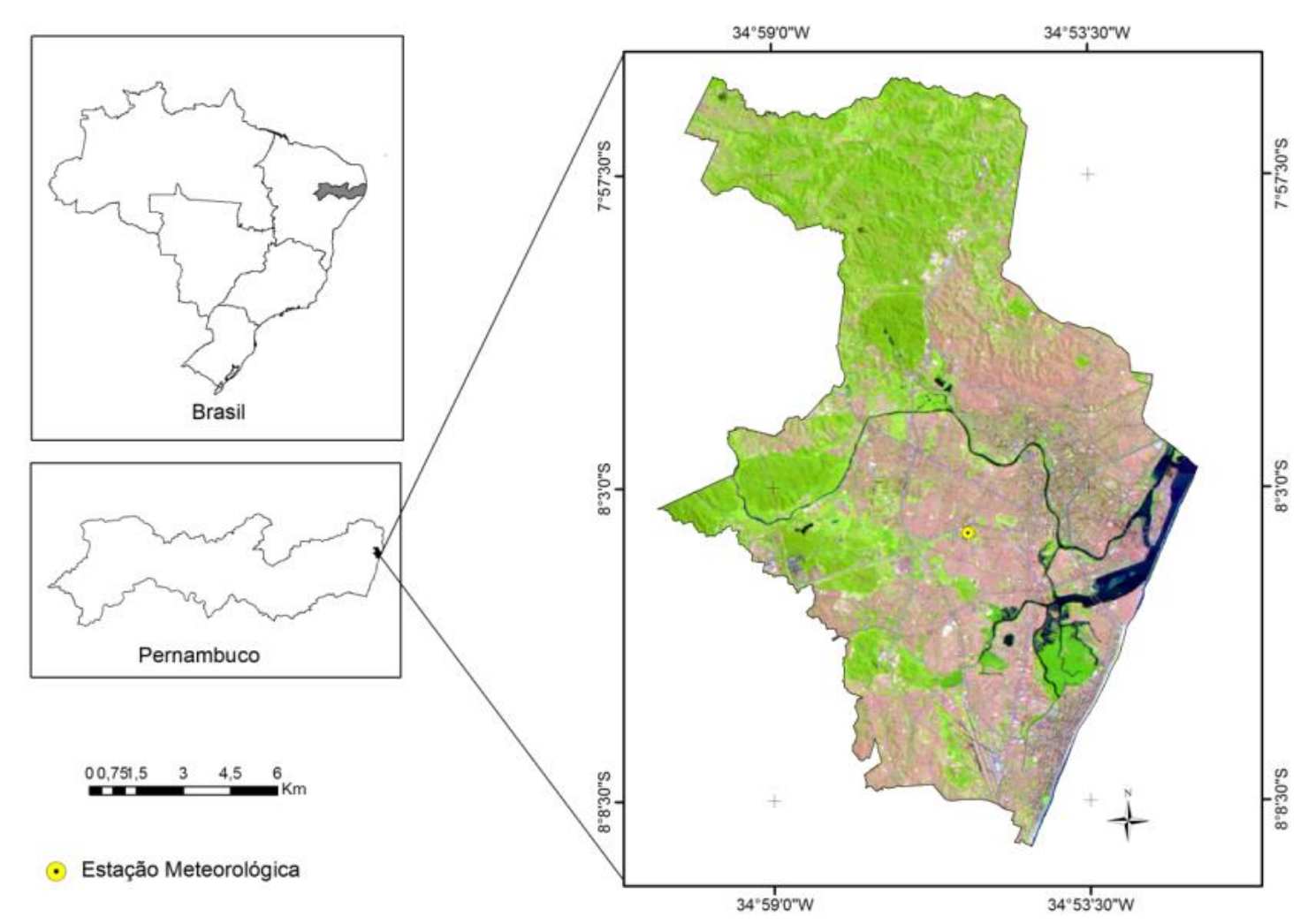

Figura 1 - Localização da área de estudo. Mapa do Brasil, mapa de Pernambuco e imagem Landsat 5 -TM destacando a cidade do Recife na composição R(5), G(4), B (3).

\subsection{Dados orbitais}

Para a realização deste trabalho foram utilizadas seis imagens digitais geradas pelo sensor Mapeador Temático (Thematic Mapper - TM), abordo do satélite Landsat 5 nos respectivos dias sequencial do ano (DSA): 216/1998, 269/2000, 238/2006, 209/2007, 249/2010 e 268/2011, e cujas principais características estão descritas na Tabela 1. 
XVII Simpósio Brasileiro de Geografia Física Aplicada

I Congresso Nacional de Geografia Física
OS DESAFIOS DA GEOGRAFIA FÍSICA NA FRONTEIRA DO CONHECIMENTO

Instituto de Geociências - Unicamp

Campinas - SP

28 de Junho à 02 de Julho de 2017

\begin{tabular}{|c|c|c|c|c|c|c|c|c|c|}
\hline \multirow{3}{*}{ Bandas } & \multirow{3}{*}{$\begin{array}{c}\text { Faixa } \\
\text { espectral } \\
(\mu \mathrm{m})\end{array}$} & \multicolumn{5}{|c|}{$\begin{array}{c}\text { Coeficientes de Calibração } \\
\left(\mathrm{Wm}^{-2} \boldsymbol{\mu m}^{-1}\right)\end{array}$} & & \multirow{3}{*}{\multicolumn{2}{|c|}{$\begin{array}{c}\mathbf{K}_{\lambda}\left(\lambda_{\mathbf{i}}\right) \\
\left(\mathbf{W m}^{-2} \mu \mathbf{m}^{-1}\right)\end{array}$}} \\
\hline & & \multicolumn{2}{|c|}{$\begin{array}{c}01 / 03 / 1984 \\
\text { até } 04 / 05 / 2003\end{array}$} & \multicolumn{2}{|c|}{$\begin{array}{c}05 / 05 / 2003 \\
\text { até } 01 / 04 / 2007\end{array}$} & \multicolumn{2}{|c|}{$\begin{array}{c}\text { Após } \\
\text { 02/04/2007 }\end{array}$} & & \\
\hline & & $\mathbf{a}$ & b & $\mathbf{a}$ & b & $\mathbf{a}$ & $\mathbf{b}$ & & \\
\hline 1 (azul) & $0,45-0,52$ & $-1,52$ & 152,10 & $-1,52$ & 193,00 & $-1,52$ & 169,00 & 1957 & 0,93 \\
\hline 2 (verde) & $0,52-0,60$ & $-2,84$ & 296,81 & $-2,84$ & 365,00 & $-2,84$ & 333,00 & 1826 & 0,274 \\
\hline 3 (vermelho) & $0,63-0,69$ & $-1,17$ & 204,30 & $-1,17$ & 264,00 & $-1,17$ & 264,00 & 1554 & 0,233 \\
\hline 4 (IV-próximo) & $0,76-0,90$ & $-1,51$ & 206,20 & $-1,51$ & 221,00 & $-1,51$ & 221,00 & 1036 & 0,155 \\
\hline 5 (IV-médio) & $1,55-1,75$ & $-0,37$ & 27,19 & $-0,37$ & 30,20 & $-0,37$ & 30,2 & 215,0 & 0,032 \\
\hline 6 (IV-termal) & $10,4-12,5$ & 1,2378 & 15,303 & 1,2378 & 15,303 & 1,2378 & 15,03 & - & - \\
\hline 7 (IV-médio) & $2,10-2,35$ & $-0,15$ & 14,38 & $-0,15$ & 16,50 & $-0,15$ & 16,50 & 80,67 & 0,012 \\
\hline
\end{tabular}

Fonte: Adaptado de Chander et al. (2007).

As cenas foram obtidas no site de geração de imagens do Instituto Nacional de Pesquisas Espaciais. O recorte da cidade do Recife compreende duas imagens referentes a órbita 214 e pontos de recobrimento da área 65 e 66 . A seleção das imagens baseou-se na disponibilidade da cobertura espacial da área e no menor percentual de nebulosidade. As cenas TM Landsat 5 foram empilhadas bandas à banda e posteriormente registradas pela correção geométrica polinomial de primeira ordem, com três pontos de controle possibilitando um erro inferior a um pixel, tomando por base a imagem disponibilizada pelo site www.landsat.org. No segundo momento foi realizado o mosaico e a exclusão dos números digitais referentes a nuvens e sombras de nuvens através da realização de uma classificação supervisionada.

O MDE (Modelo Digital de Elevação) da área em estudo foi adquirido junto ao site da Embrapa Monitoramento por Satélite (Brasil Relevo) no produto SRTM (Shuttle Radar Topography Mission) referente aos mosaicos SB-25-Y-C e SC-25V-A. As imagens foram reamostradas de sua resolução original 90 x 90 m para 30 × 30 m, sendo utilizada como base no cômputo da transmitância instantânea e pressão atmosférica em cada pixel.

As datas das imagens compreendem um intervalo de 13 anos e apresentam dados de épocas semelhantes, referentes às estações do inverno. A Figura 2 apresenta o gráfico da precipitação nas datas em análise e nos 3 dias que antecederam a passagem do satélite, onde é possível identificar nas datas 216/1998 e 209/2007, 1,0 e 2,0 mm respectivamente. Nas demais datas que representam a passagem do satélite não foi registrado eventos de precipitações. 


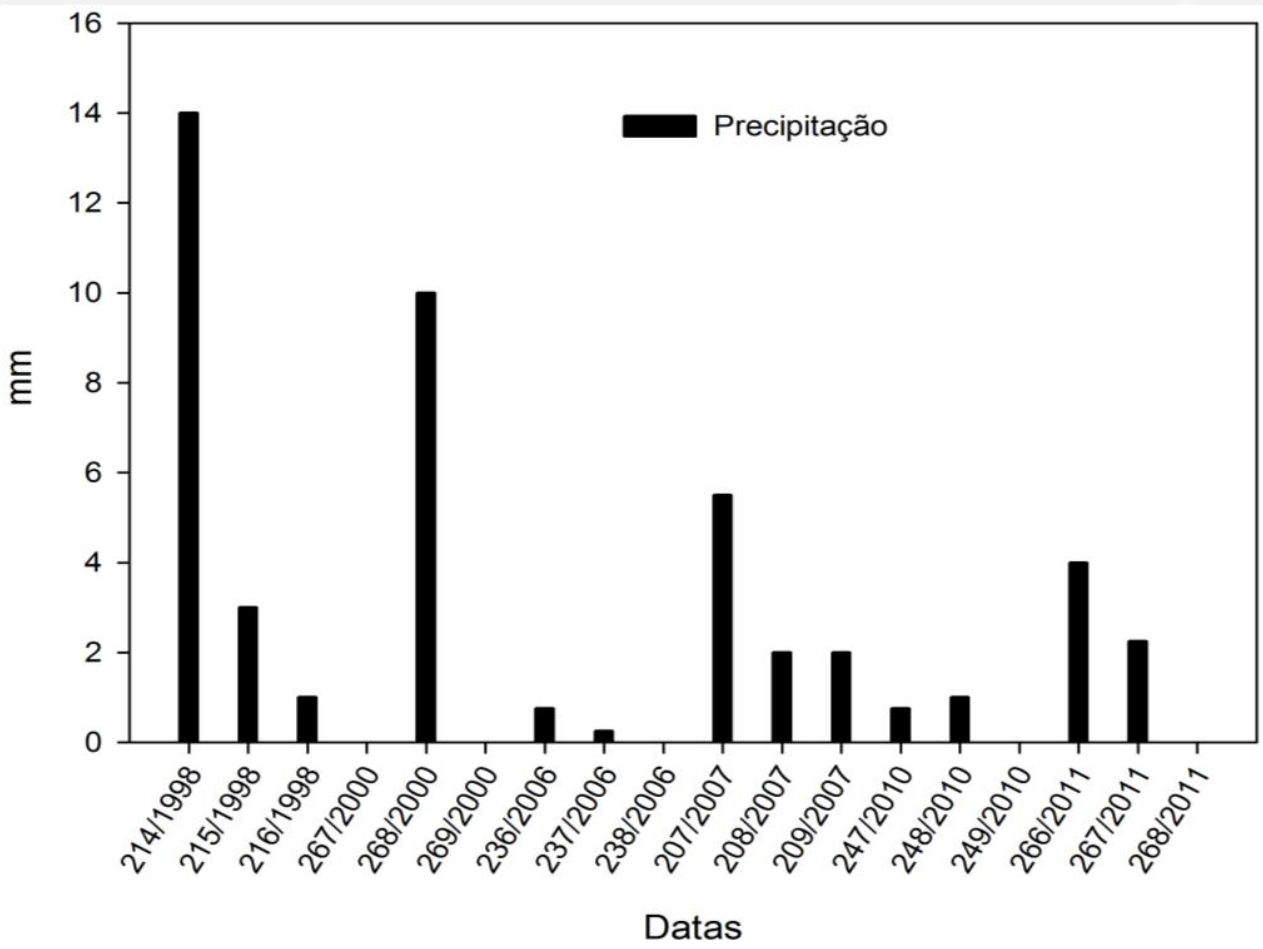

Figura 2 - Precipitação acumulada nos três dias antecedentes a passagem do satélite.

\subsection{Processamento}

$\mathrm{Na}$ fase do processamento das imagens de satélite e cômputo dos parâmetros do balanço de energia como também na montagem final do layout e geração dos mapas utilizou-se o software Erdas Imagine versão 9.3 executado a ferramenta Model Maker e o ArcGis versão 10.1 (Ambos com Licença do Departamento de Ciências Geográficas da UFPE. Os valores estatísticos das imagens foram obtidos através da conversão para o formato ASCII usadas para geração de tabelas que posteriormente foram representadas em gráficos processados no programa SigmaPlot 10.0.

Na obtenção do fluxo de calor no solo, a etapa inicial fundaentou-se na calibração radiométrica, processo de conversão do número digital - ND de cada pixel da imagem, em radiância espectral monocromática, Li, que representa a energia solar refletida por cada pixel por unidade de área, de tempo, de ângulo sólido, medida a nível do satélite Landsat para as bandas 1,2,3, 4, 5 e 7; para a banda 6, essa radiância representa a energia emitida por cada pixel, e para cada banda a radiância monocromática foi obtida pela equação (Markham e Baker, 1987):

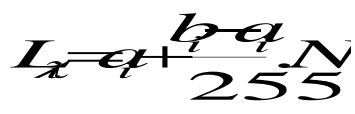


em que $a_{i}$ e $b_{i}$ são as radiâncias espectrais mínima e máxima ( $\left.\mathrm{W} \mathrm{m}^{-2} \mathrm{sr}-1 \mu \mathrm{m}^{-1}\right)$, ND é a intensidade do pixel e i corresponde às bandas $1,2, \ldots ., 7$, do TM Landsat 5 .

As etapas seguintes relacionadas a calibração radiométrica e estimativa das componentes do balanço de energia são descritas em (MOREIRA, 2014) e (Silva et al. 2006). A estimativa do fluxo de calor no solo foi computado com o uso do saldo de radiação instantâneo $(\mathrm{Rn})$ e uma relação empírica desenvolvida por Bastiaanssen (2000), que representa valores próximos ao meio-dia, conforme equação abaixo:.

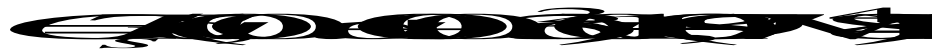

em que: Ts é a temperatura da superfície $\left({ }^{\circ} \mathrm{C}\right)$, é o albedo da superfície sendo calculado em função do $\alpha_{\text {toa }}$ o albedo planetário e a transmissividade atmosférica $\tau_{\mathrm{sw}}$, em condições de céu claro é calculada em função da pressão atmosférica e da água precipitável (ASCE-EWRI, 2005; ALLEN et al., 2007a; GOMES et al., 2009; SILVA et al., 2011). NDVI ( Índice de Vegetação da Diferença Normalizada), definido pela razão da diferença pela soma das reflectividades dos canais do infravermelho próximo ( $\left.\rho_{\text {iv }}\right)$ e vermelho $\left(\rho_{v}\right)($ PONZONI e SHIMABUKURO, 2007).

\section{Resultados e discussões}

A Figura 2 apresenta os valores das médias estatísticas e desvio padrão para os anos em análise. As datas 216/1998 e 209/2007 apresentaram-se com as menores médias de $\mathrm{G}$, intervalos próximos a $50 \mathrm{~W} \mathrm{~m}^{-2}$ e desvio padrão variando entre 32 e $70 \mathrm{~W} \mathrm{~m}^{-2}$ e 35 e $68 \mathrm{~W} \mathrm{~m}^{-2}$ respectivamente, sendo estes as menores amplitudes apresentadas quando comparado com os demais anos. Entretanto, evidencia-se um distanciamento dos valores em relação à média, onde tem-se como fator determinante os diversos tipos de coberturas presentes na superfície urbana, proporcionando assim padrões diferenciados de refletividade e absorção térmica.

Em virtude desses padrões, os alvos vegetação, corpos hídricos e superfícies impermeáveis distribuídos na superfície apresentam valores de $\mathrm{G}$ diferenciados e com alta amplitude entre os intervalos, que podem ser explicados pelo processo de aquecimento por condução e convecção. Sendo assim, elucida-se o distanciamento dos resultados encontrados e o favorecimento do maior percentual do $\mathrm{G}$ usado para aquecimento e, consequentemente, o aumento da temperatura da superfície. A maior média foi encontrada na data 268/2011, $70 \mathrm{~W} \mathrm{~m}^{-2}$ e com desvio padrão entre $50 \mathrm{~W} \mathrm{~m}^{-2}$ e $90 \mathrm{~W} \mathrm{~m}^{-2}$ corroborando com a influência da heterogeneidade da superfície na distribuição dos valores e o distanciamento da média. 


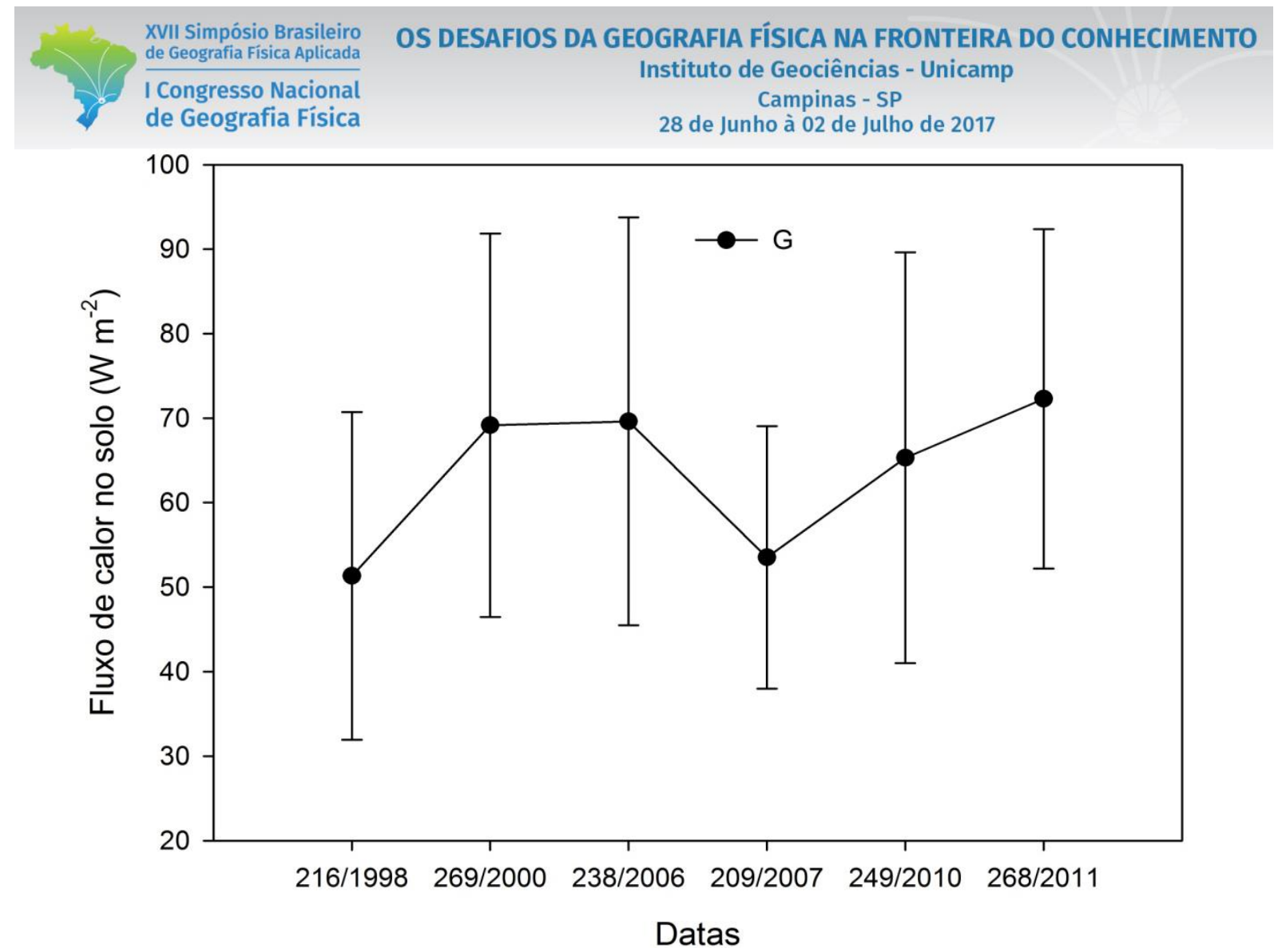

Figura 2 - Gráfico dos valores médios e desvio padrão do fluxo de calor no solo nas datas 216/1998, 269/2000, 238/2006, 209/2007, 249/2010 e 268/2011

A variação espacial dos valores de $G$ representado na Figura 3, elucidam em todas as cenas a menor magnitude nas áreas providas de vegetação localizadas no setor oeste das imagens com tonalidade verde limão e amarelo, enquanto o setor leste destacados na tonalidade vermelha localizados nas áreas com predominância de coberturas impermeáveis e com elevado adensamento urbano, apresentaram os maiores valores do fluxo de calor no solo, proporcionando o surgimento de ilhas de calor, fenômeno comum em áreas urbanas (WENG et al., 2004).

As cenas referentes as datas 269/2000, 238/2006, 249/2010 e 268/2011 apresentam em toda mancha urbana uma mudança significativa nos padrões de $\mathrm{G}$, com valores superiores a $75 \mathrm{~W} \mathrm{~m}^{-2}$, seguidos dos corpos hídricos, com valores de aproximadamente $205 \mathrm{~W} \mathrm{~m}^{-2}$, enquanto as feições de vegetação permaneceram com os menores valores, oscilando entre 31 e $45 \mathrm{~W} \mathrm{~m}^{-2}$, representados na tonalidade verde limão.

As datas 216/1998 e 209/2007 apresentaram os menores índices, sendo atribuído aos baixos valores das cartas de temperatura da superfície assim como a menor incidência da radiação solar registradas nas datas, conforme citado em capítulos anteriores. Entretanto o comportamento da superfície urbana permaneceu 


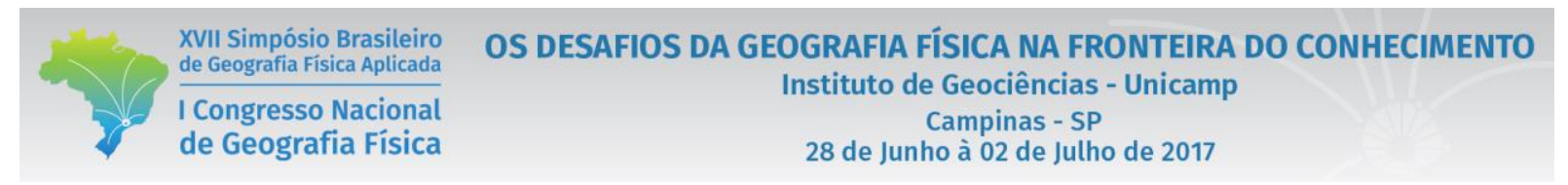

com os maiores valores, oscilando entre 46 e $60 \mathrm{~W} \mathrm{~m}^{-2}$ representada na tonalidade amarela, enquanto as áreas providas de vegetação apresentaram padrão semelhante aos anos em análise. Bezerra (2006) e Santos et al. (2010) encontraram valores de $\mathrm{G}$ com intervalos de aproximadamente $100 \mathrm{~W} \mathrm{~m}^{-2} \mathrm{em}$ área urbana e valores inferiores a $40 \mathrm{~W} \mathrm{~m}^{-2}$ nas áreas providas de vegetação através do TM Landsat 5 , em datas distintas.
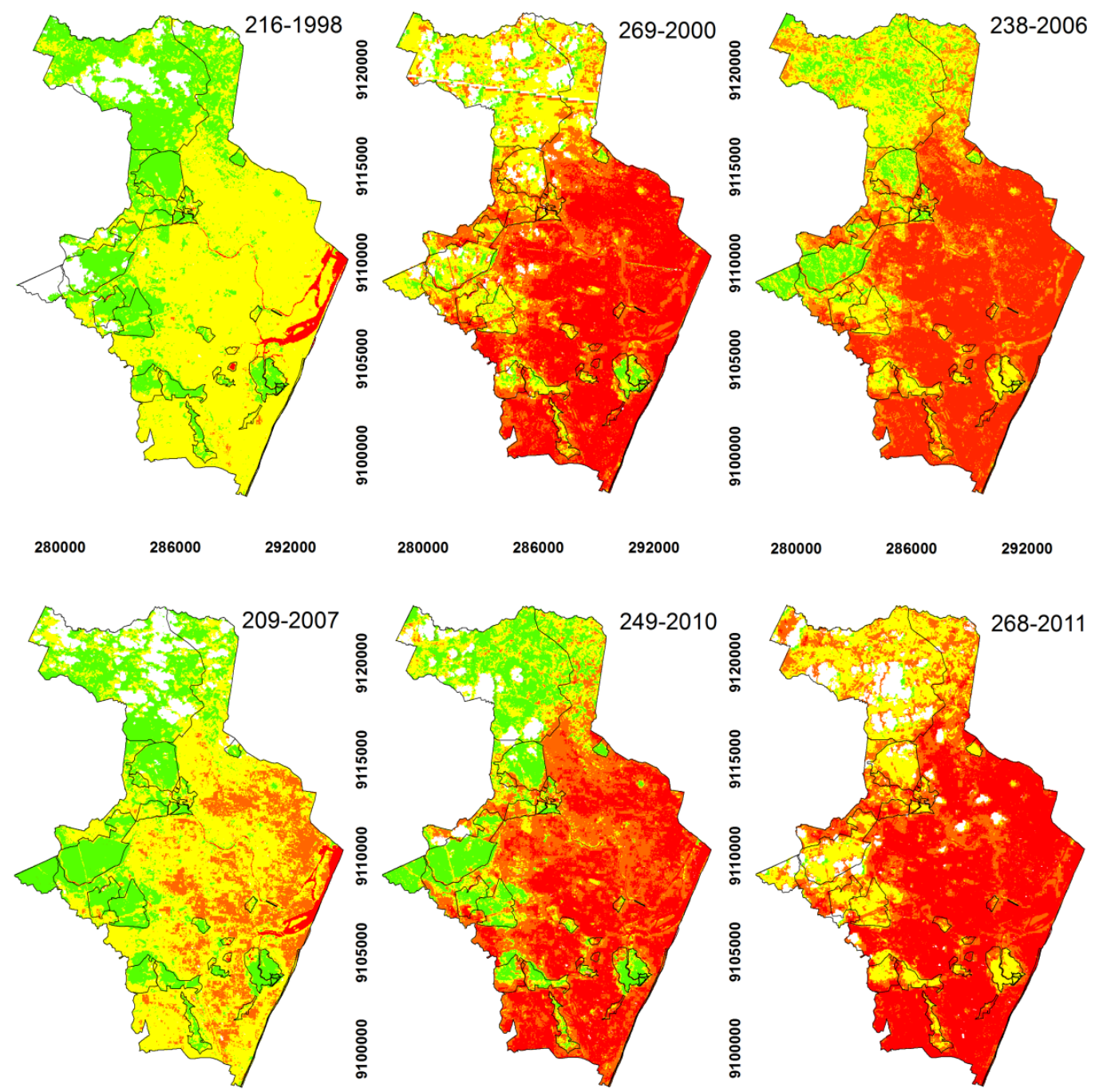

\section{Fluxo de calor no solo $\left(\mathrm{W} \mathrm{m}^{-2}\right)$}

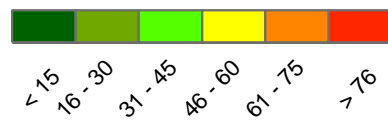

Figura 3 - Carta temática da distribuição espacial do fluxo de calor no solo nas datas 216-1998, 269-2000, 238-2006, 209-2007, 249-2010 e 268-2011 
A Tabela 1 lista a percentagem de pixels em cada classe do fluxo de calor no solo. Observa-se que as classes, $\left(46<\mathrm{G}<60 \mathrm{~W} \mathrm{~m}^{-2}\right.$ ) são as mais frequentes nas datas 216/1998 e 209/2007, destacando percentuais entre 64,50 e $50,22 \%$, respectivamente, enquanto a classe com valores $\left(\mathrm{G}>76 \mathrm{~W} \mathrm{~m}^{-2}\right)$ apresentou o maior percentual na data 268/2011 (51,21\%).

Tabela I - Distribuição percentual das classes do fluxo de calor no solo $(\mathrm{G})$ para as datas em análise.

\begin{tabular}{|c|c|c|c|c|c|c|}
\hline$G\left(W m^{-2}\right)$ & $\begin{array}{c}216 / 1998 \\
(\%)\end{array}$ & $\begin{array}{c}269 / 2000 \\
(\%)\end{array}$ & $\begin{array}{c}238 / 2006 \\
(\%)\end{array}$ & $\begin{array}{c}209 / 2007 \\
(\%)\end{array}$ & $\begin{array}{c}249 / 2010 \\
(\%)\end{array}$ & $\begin{array}{c}268 / 2011 \\
(\%)\end{array}$ \\
\hline$<15$ & 0 & 0,01 & 0 & 0,04 & 0,03 & 0 \\
\hline $16<\mathrm{G}<30$ & 0,62 & 0,05 & 0,02 & 0,02 & 0,21 & 0 \\
\hline $31<\mathrm{G}<45$ & 32,06 & 7,02 & 10,47 & 28,45 & 20,10 & 0,73 \\
\hline $46<\mathrm{G}<60$ & 64,50 & 30,64 & 22,54 & 50,22 & 18,18 & 22,78 \\
\hline $61<\mathrm{G}<75$ & 0,61 & 53,55 & 21,52 & 19,47 & 31,58 & 25,28 \\
\hline $\mathrm{G}>76$ & 2,03 & 8,73 & 45,45 & 1,80 & 29,90 & 51,21 \\
\hline
\end{tabular}

A Figura 4 elenca a relação entre o G e o NDVI na data 268/2011 para seis alvos selecionados, três correspondentes a unidades de conservação, dois para superfícies desprovidas de vegetação e um referente a corpo hídrico. É possível constatar uma relação inversa entre os menores valores de G com intervalos entre 51 e $53 \mathrm{~W} \mathrm{~m}^{-2}$ para os alvos com índices de NDVI superiores a 0,6 localizados nos fragmentos de mata, enquanto os valores de $\mathrm{G}$ superiores a $71 \mathrm{~W} \mathrm{~m}^{-2}$ foram encontrados nos alvos com índices de NDVI inferior a 0,2, em destaque o Shopping Recife e o Carrefour.

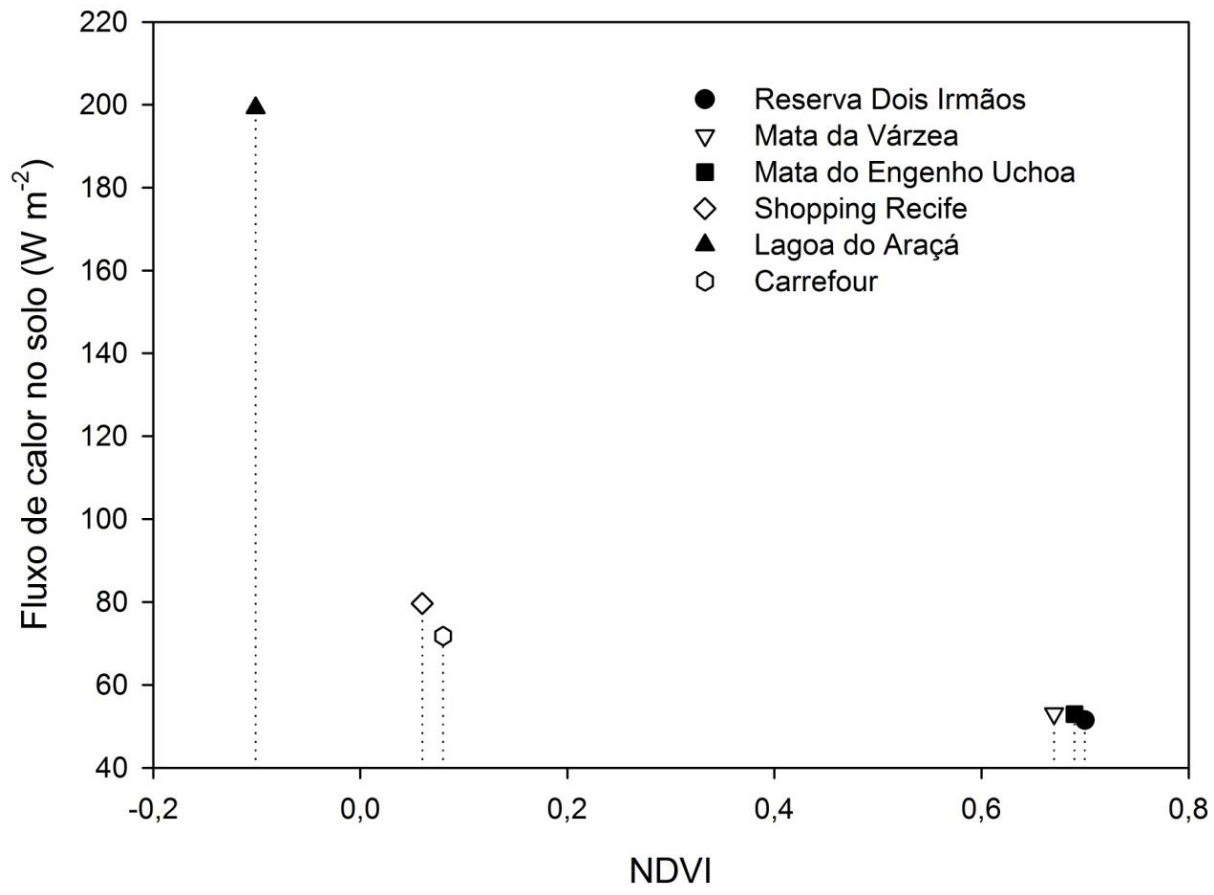


Figura 4 - Dispersão entre o fluxo de calor no solo e o índice de vegetação NDVI para os alvos: Manguezal do Pina, Carrefour, Shopping Recife, Aeroporto e Ceasa na data 268/2011.

O alvo corpo hídrico, localizado na lagoa do Araçá apresentou valor de G superior a $199 \mathrm{Wm}^{-2}$ e com NDVI negativo. Em concordância com os valores encontrados nessa pesquisa, Giacomoni (2005) encontrou através de imagens NOAA para o estado do Rio Grande do Sul intervalos entre 93,3 W m ${ }^{-2}$ para classe área urbana, $39 \mathrm{Wm}^{-2}$ na classe floresta e $197,3 \mathrm{~W} \mathrm{~m}^{-2}$ no alvo lagoa.

Com exceção da superfície líquida representada no alvo lagoa do Araçá, os alvos com maior percentual de energia disponível para aquecer a superfície são os que apresentam maior intervenção antrópica e consequentemente favorecem o surgimento de feições com maiores valores de temperatura da superfície.

\section{Conclusão}

O presente trabalho analisa a influência da superfície urbana na quantidade de calor armazenado no solo em seis imagens do sensor TM Landsat 5 referente a cidade do Recife. Foi possível representar os valores espacializados em todas as cenas em estudo, permitindo assim, contemplar a distribuição espacial dos valores encontrados, podendo ser destacado o setor leste da cidade com predomínnio de impermeabilização da superfície, contemplados por materiais empregados com alto potencial de absorção e transferência de calor no solo, apresenado valores superiores a $70 \mathrm{~W} \mathrm{~m}^{-2}$. Essa energia empregada para aquecimento contribui para a formação das ilhas de calor, enquanto as áreas com predomínio de vegetação situados nos recortes com fragmentos de mata e manguezal apresentou intervalos entre 45 a $60 \mathrm{~W} \mathrm{~m}^{-2}$. Essas informações poderão subsidiar o planejamento urbano em uma tomada de decisão, visando a mitigação de recortes espaciaiss climaticamente confortáveis.

\section{Bibliografia}

BASTIAANSSEN, W. G. M. Sebal - Based sensible and latent heat fluxes in the irrigated Gediz basin, turkey. Journal of Hydrology, v.229, p.87-100, 2000.

BASTIAANSSEN, W.G.M.; MENENTI, M.; FEDDES, R.A.; HOLTSLAG, A.A.M.A. Remote Sensing Surface Energy Balance Algorithm for Land (SEBAL) 1.Formulation. Journal of Hydrology, v. 212-213, p. 198-212, 1998a.

BEZERRA, B. G. Obtenção da evapotranspiração diária no cariri cearense utilizando imagens landsat 5-TM e o algoritmo Sebal. 135f. dissertação (mestrado em meteorologia) - Universidade Federal de Campina Grande, Campina Grande, 2006. 
BROWN, M. J. Urban parameterizations for mesoscale meteorological models. Mesoscale Atmospheric Dispersion, Ed., Boybeyi, wit press, 2000.

GIACOMONI, M. H. Estimativa da evapotranspiração regional por meio de técnicas de sensoriamento remoto integradas a modelos de balanço de energia: aplicação no estado do Rio Grande do Sul. 193 p. 2005. Dissertação (mestrado) - Universidade Federal do Rio Grande do Sul, Porto Alegre.

GRIMMOND, C. S. B.; OKE, T. R. Evapotranspiration rates in urban areas. impacts of urban growth on surface water and groundwater quality (symposium hss. birmingham, july 1999). Iahs publ. n. 259.1999a.

Aerodynamic properties of urban areas derived from analysis of surface form. Journal of Applied Meteorology, v. 38, p. 1262-1292, 1999 b.

MAITELLE, G. T. Balanço de energia estimado para cidade de cuiabá: uma abordagem de balanço de energia pelo método de bowen. Fórum Patrimônio, v.4, n.1, p.1-34, 2010.

MONTEIRO, C. A. F., Por um Suporte Teórico e Prático para Estimular Estudos Geográficos de Clima Urbano no Brasil. Geosul, ano V, n.9, p.7-19, $1^{\circ}$ Semestre. 1990.

MOREIRA, E. B. M. Balanço de energia e evapotranspiração na cidade do Recife por sensoriamento remoto. Tese. Universidade Federal de Pernambuco, 155p, 2014.

PONZONI, F. J.; SHIMABUKURO, Y. E. Sensoriamento remoto no estudo da vegetação. São José dos Campos: Parêntesis, 2007. 136 p.

ROBERTS, S. M.; OKE, T. R.; VOOGT, J. A.; Grimmond, C. S. B.; Lemonsu, A. 1984: Energy Storage in a European City Center, Météo-France, Toulouse, France.

SANTOS, T. V.; FONTANA, C, D.; ALVES, R. C. M. Avaliação de fluxos de calor e evapotranspiração pelo modelo Sebal com uso de dados do sensor Aster. Pesquisa agropecuária brasileira, Brasília, v.45, p.488-496, 2010 .

SILVA, B. B. da., BEZERRA, M. V. C. Determinação dos fluxos de calor sensível e latente na superfície utilizando imagens TM - Landsat 5. Revista Brasileira de Agrometeorologia, v. 14, n. 2, p. 174-186, 2006.

WENG, Q.; DENGSHENG, L.; SCHUBRING, J. Estimation of land surface temperature-vegetation abundance relation ship for urban heat island studies. Remote Sensing of Environment, v.66, n.23, p. 467-483, 2004. 